\title{
Arterial Pulse Wave Velocities are Unchanged Following 12 Weeks of Circuit Weight Training
}

Joseph D. Jacquez, Steven A. Romero, Eren R. Sanborn, Gilbert Moralez, Dong Dong Lui, Donovan L. Fogt, William H. Cooke

University of Texas at San Antonio, Laboratory for Applied Autonomic Neurophysiology

Int J Exerc Sci 2(1): S12, 2009. Arterial stiffness is decreased after vigorous endurance training and increased after high-intensity resistance training. The effects of a combined program of moderate endurance and resistance exercise on arterial stiffness have not been determined. PURPOSE: To determine whether12 weeks of circuit weight training will decrease both central and peripheral arterial stiffness as estimated from pulse wave velocity (PWV). METHODS: Thirteen males and eight females (age 22 \pm 2 , height $162 \pm$ $8 \mathrm{~cm}$, weight $78 \pm 20 \mathrm{~kg})$ were assigned to control $(\mathrm{n}=10)$ or exercise $(\mathrm{n}=11)$ groups. Aerobic capacity and muscular strength were assessed before and at the end of the 12 week period. Arterial pressures and PWV (Doppler) were recorded every four weeks. Velocities from the carotid to femoral artery and from the femoral to dorsalis pedis artery were used as estimates of central and peripheral stiffness. RESULTS: Muscular strength increased by $26 \%(P=.001)$ and $\mathrm{VO}_{2}$ max increased by $17 \%(P=.06)$ following circuit training in the exercise group, but was unchanged for controls. Circuit weight training did not affect arterial pressures, (systolic $=117 \pm 3$, diastolic $=74 \pm 3 \mathrm{mmHg}$; pooled across groups), or central and peripheral PWV (central PWV $=6.2 \pm 0.6$, peripheral PWV $=9.5 \pm 0.7 \mathrm{~m} \cdot \mathrm{s}^{-1}$; pooled across groups). CONCLUSIONS: In contrast to other reports of increases in arterial stiffness following high-intensity resistance training, increases in muscular strength following moderate-intensity exercise in the current study were not associated with increased arterial stiffness. Circuit training may be an appropriate exercise prescription to increase muscular strength for patients at risk for peripheral artery disease.

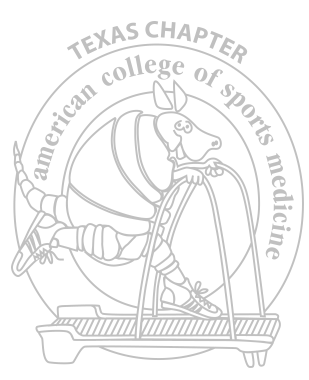

S12 